\title{
Mental Health Review Tribunals: time for reform?
}

\author{
Carole Kaplan and Paul Ralph
}

The paper by Shah \& Oyebode (1996) on the use of Mental Health Review Tribunals highlights a number of new concerns about their present working and effectiveness. They add to the wider concerns being voiced about the organisation and structure of the MHRT system and its perceived independence from the Department of Health, about standards of hearing accommodation and the handling of complaints, and about the impact which the acute funding and staffing difficulties within the system are having on the effective working of the tribunals themselves.

The Council on Tribunals, which supervises the tribunal system, has come across recent evidence of increasing delays, both in the hearing of Section 3 cases and in restricted cases in the special hospitals, of low morale among tribunal support staff who are working under acute pressures, and of the chairmen and members of tribunals having to take on administrative duties because of the absence of a hearing clerk at many hearings. In addition, concern has been expressed about the increasing demands on mental health service professionals who provide reports and evidence for the tribunals. All these concerns have become pressing at a time when the number of persons detained under the Mental Health Act, and the number of applications to MHRTs, is on the increase. And they are not eased by the prospect of a further increase in their workload under the 'supervised discharge' provisions of the Mental Health (Patients in the Community) Act 1995

The Council has also joined with others in expressing disquiet about managers' reviews which operate in parallel with the tribunals to allow more informal consideration of individual cases. It has noted the apparent confusion at all levels between the respective roles of managers reviews and MHRTs, not least in the mind of patients, the uncertainty among managers as to their powers, and the inconsistency of approach as to who should take part in the review process and how it should be conducted.

The announcement by the Secretary of State for Health in September 1996 that the Govern- ment is taking action to reduce delays, by improving the administrative support given to MHRTs and by ensuring that hospital staff meet deadlines for providing reports to the tribunals, is viewed by the Council as an encouraging response to the general concern about delays. The Council also welcomes the Government's intention, as soon as legislation permits, to abolish the hospital managers' powers to discharge detained patients. Pending this change, the department are already consulting on a revised Code of Practice which will, among other things, improve the guidance given to hospital managers about their functions and responsibilities for the review process.

The Council has not been alone in pointing to shortcomings in the MHRT system. There is still widespread unease about the present role and functions of MHRTs, particularly in restricted cases, and about their place in the decisionmaking process. More recently, the Report of the Independent Panel of Inquiry on the Jason Mitchell case (1996) has recommended a number of procedural and evidential changes, and raised questions about the constitution of the tribunals themselves, including the role of lay members. The Report has joined the calls from many other quarters for reform of the Mental Health legislation itself. To that must be added the case for research into why so many detained patients do not exercise their right to appeal.

\section{References}

SHAH, M. \& OYEBODE, F. (1996) The use of Mental Health Review Tribunals. Psychiatric Bulletin, 20, 653-655.

INDEPENDENT PANEL OF INQUIRY (1996) The Case of Jason Mitchell: Report of the Independent Panel of Inquiry. London: Duckworth.

*Carole Kaplan, Fleming Nuffield Unit, Burdon Terrace, Newcastle upon Tyne NE2 3AE; and Paul Ralph, Secretariat, Council on Tribunals, 22 Kingsway, London WC2B 6LE

*Correspondence 